\title{
DESARTICULACIÓN DE DISCURSOS NACIONALISTAS EN EL CINE DE AUTOR BOLIVIANO: 3B'S Y SOCAVÓNCINE
}

\section{Mariana Lacunza Mendizábal}

\section{RESUMEN}

Distinta a México, Argentina y Brazil, Bolivia tiene una industria cinematográfica poco desarrollada que no ha logrado consolidarse por varias razones. Entre éstas está la falta de apoyo estatal, el escaso desarrollo profesional en estas áreas y una carencia de cultura cinematográfica y visual en general. Sin embargo, durante la última década, la industria cinematográfica boliviana ha sido partícipe de logros importantes gracias a la aparición de las nuevas tecnologías. Películas digitales hechas por una nueva generación de jóvenes directores reconocidos globalmente se han desarrollado en tres ramas distintas: a) cine de autor, b) cine documental y c) cortometrajes. Al mismo tiempo, la producción de este tipo de filmes se apoya en un esfuerzo colectivo, como es el caso de RAV (Rojo, Amarillo y Verde, 2006) de Rodrigo Bellot, Martín Bolulocq y Sergio Bastani y aquellos filmes producidos por el colectivo SocavónCine desde el año 2013. Este artículo busca explorar cómo el más reciente cine boliviano de autor desarticula discursos de identidad nacional al deconstruir oposiciones binarias. Además, este artículo busca examinar la aplicabilidad del cine de autor y de las prácticas colaborativas en los "cines pequeños" o "small cinemas" al comparar y contrastar ambos grupos a través del análisis de las formas de producción y corrientes estéticas.

Palabras clave: Cine Boliviano, Industrias Cinematográficas Pequeñas, Cine Latinoamericano, Cine Digital, Discursos Nacionales, Cine de Autor, Cine Colectivo, SocavónCine.

DOI: $10.23881 /$ idupbo.017.2-7e 